Citation: Dyer, K. \& dasNair, R.* (2013). Talking about sex after traumatic brain

injury: Perceptions and experiences of multidisciplinary rehabilitation processionals.

Disability \& Rehabilitation. doi:10.3109/09638288.2013.859747

\title{
Talking about sex after traumatic brain injury: perceptions and experiences of multidisciplinary rehabilitation processionals
}

\author{
Kerry Dyer ${ }^{1}$ and Roshan das Nair ${ }^{2,3}$ \\ IInstitute of Health, Life and Social Sciences, University of Lincoln, Lincoln, UK, ${ }^{2}$ Division of \\ Psychiatry and Applied Psychology and ${ }^{3}$ Division of Rehabilitation \& Ageing, University of \\ Nottingham, Nottingham, UK
}

\begin{abstract}
Keywords Rehabilitation, sexuality, traumatic brain injury Abstract

Purpose: Research indicates that although $50-60 \%$ of people who have had a traumatic brain injury (TBI) experience changes in sexual functioning, sexuality issues remain largely unaddressed in rehabilitation. This study aimed to explore rehabilitation professionals' perceptions and experiences of discussing sexuality with service-users who have had a TBI. Method: Purposeful sampling was used to recruit 24 participants from two local National Health Service trusts and from a national charity. Four focus groups were conducted with pre-existing groups of professionals, using a semi-structured interview schedule. Focus group data were transcribed verbatim and analysed using thematic analysis. Results: Six main themes were derived from the analysis: (1) sexuality after TBI is a specialist issue; (2) sexuality is a sensitive subject; (3) practicalities of discussing sexuality; (4) roles and responsibilities; (5) dilemmas about risk and vulnerabilities; and (6) organisational and structural issues. Conclusions: Our findings suggest that a more proactive approach to addressing sexuality issues be taken by incorporating sexuality into assessments and by having sexuality information available for service-users. Support for professionals is also needed in the form of the development of policy, on-going training and supervision.
\end{abstract}

\section{Implications for Rehabilitation}

- Rehabilitation professionals find it difficult to deal with issues of sexuality following TBI, and the reasons for this are complex and interrelated.

- To provide holistic care, a more proactive approach to addressing sexuality issues should be taken. Professionals do not need to be an expert in sexual issues to open dialogue.

- Sexuality discussions should be incorporated into assessments, and written information should be available for service-users. Further training for professionals and organisational policy change is sometimes required to effectively deal with sexuality issues.

\section{Introduction}

Sexuality has been defined as the way that people experience themselves and each other as sexual beings [1], encompassing sexual activity, sexual orientation, gender identity and roles, eroticism, pleasure, intimacy and reproduction [2]. Sexual wellbeing is increasingly being considered as an integral component of the total well-being of a person; for example, it is highlighted as a component of healthcare in the International Classification of Functioning, Disability and Health [3], and is also referred to in the UK Department of Health's White Paper: Healthy Lives, Healthy People [4]. Sexual disturbances and dysfunction can cause frustration, anxiety, depression and affect overall quality of life for both the service-user and their partner(s) [5].

A traumatic brain injury (TBI) occurs when an outside force causes temporary or permanent damage to the brain.

Address for Correspondence: Kerry Dyer, Institute of Health, Life and Social Sciences, University of Lincoln, Lincoln, UK. Tel: p44 (0)1522 886029. E-mail: kerry_dyer@hotmail.co.uk
For individuals with TBI, disruption to sexuality has been believed to be "more the rule than the exception"[6, p. 1]. More formal findings have indicated that $50-60 \%$ of people report some level of disruption to sexual function post-TBI [7-10]. The reasons for changes in sexuality are complex and multifaceted, but TBI has the potential to disrupt social and relationship skills, body image and self-esteem, behavioural control, libido and the physical capacity to perform sexually [9-13]. Studies on post-TBI marital stability show divorce or separation rates ranging from $15 \%$ to $78 \%$ [14-20].

However, despite acknowledgement of widespread disturbance in sexual functioning after TBI, research indicates that sexuality is a neglected area in TBI rehabilitation. For example, only small proportions (ranging from 0 to $11 \%$ ) of people with TBI and their family members report that professionals made inquiries about whether they had any sexual concerns [9,21]. As a consequence, many people with TBI may be suffering from undetected but treatable sexual problems [7].

A survey of 129 rehabilitation professionals [22] found that although $79 \%$ thought that sexuality ought to be addressed as part of the holistic care of persons with TBI, only $9 \%$ said that they 
address the topic on a regular basis. This highlights a conflict between staff ideology and practice regarding discussing and addressing service-users' sexuality, which has been supported by findings from the literature [23-25]. This is inadequate given that sexuality has been found to be predictive of overall adjustment to disability, self-esteem and overall quality of life $[13,26]$.

Research indicates that professionals may be reluctant to engage service-users in discussions about sexuality after TBI for a number of reasons, including personal embarrassment, lack of knowledge and training, lack of time and resources, believing it is not their responsibility, lack of policy and the lack of a systematic approach to sexual rehabilitation post-TBI [23-25,27,28]. Furthermore, research has indicated that professionals tend to take a reactive approach, only addressing it if the service-user raises it first $[22,23]$.

Previous research has largely been quantitative in nature, but researchers have suggested that qualitative research would provide a richer understanding of communication about sexual issues [24]. Indeed, only one qualitative study has investigated the subjective views of professionals about the issue [25]. However, with this study being conducted 13 years ago in Israel, generalisability of the findings to current healthcare settings in the UK is potentially limited. Qualitative research in other healthcare settings (including a recent systemic review by Dyer \& das Nair [29]) has reiterated some of the abovementioned reasons for lack of discussion regarding sexuality. However, a deeper understanding of this specifically within TBI settings is required.

\section{Methods}

\section{Research design}

The research was conducted using a qualitative design, and the data were collected using focus groups with teams of rehabilitation professionals that already work together. Focus groups are useful for exploring people's knowledge, attitudes and experiences [30]. Focus groups also offer the opportunity to observe how people interactively construct meanings: how opinions are formed, expressed, defended and modified within the context of discussion and debate with others [31]. It was felt that data generated in the context of interaction between participants (as well as with the interviewer) offer a clear advantage over individual interviews [32].

\section{Procedure}

A semi-structured interview schedule was developed to guide and open-up dialogue about sexual issues post-TBI. This ensured that the participants across the different focus groups not only had the opportunity to discuss similar topics but also had sufficient flexibility to allow the interviewer and participants to expand on pertinent areas. The questions were determined by the areas lacking in the literature and aimed to explore perceptions and experiences of communication about patient sexuality, as well as considerations of what might help or hinder the communication process. Beyond this, a low moderator approach was adopted.

Professionals who work with people with TBI were recruited either from the NHS (local TBI or neurorehabilitation teams) or from a national charity, which supports people affected by brain injury. Initially, managers (or senior members of staff) were contacted about the study, who subsequently distributed information about the study to professionals within their teams. A purposive sample of 24 participants (6 males and 18 females) took part in one of four focus groups (FG1, FG2, FG3 and FG4), stratified by the team in which they work. Focus groups contained five, seven, four and eight participants, respectively. Participants were: occupational therapists $(n=6)$, support workers $(n=5)$, psychological therapists $(n=3)$, physiotherapists $(n=2)$, case managers $(n=2)$, a medical doctor $(n=1)$ and "other"therapists $(n=5)^{1}$. Their years of experience working with clients with a TBI ranged from one year to over 20 years.

Focus groups were held at the participants' team base between usual hours of working practice and were facilitated by the first author (K. D.). The sessions lasted an average of 40 min (excluding time taken to complete consent forms and collect demographic information). The focus groups were audio-recorded to aid verbatim transcription. A modified Jeffersonian transcription style was employed ${ }^{2}$ [33]. As recommended in the literature [34,35], field notes on non-verbal behaviour and group interactions were also made and incorporated into the transcripts.

\section{Data analysis}

A thematic analysis was conducted at the manifest (i.e. surface) level, based on the six-stage process outlined by Braun \& Clarke [36]. Transcriptions were initially read and re-read, noting down initial codes and categories in the right margin. Initial codes were then collated into themes. Finally, a thematic map was generated, incorporating main themes and subthemes. The analysis was conducted within a critical-realist paradigm.

\section{Quality assurance measures}

Faithful to the aims of qualitative research, we sought to ensure quality by establishing trustworthiness of the findings

[37]. Both qualitative [37,38] and thematic analysis specific [36] guidelines were followed. This study employed a number of techniques, including: (1) researcher triangulation, by comparing independently coded transcripts and themes with the second author (R. d. N.); (2) maintaining an audit trail throughout the analytical process, to provide a transparent pathway for the researchers and others to follow the code and theme development; (3) including verbatim quotations from participants, to enable the reader to assess the credibility of findings; and (4) maintaining a reflective diary, to consider the impact of the interviewer upon the research from the conceptualisation stage through to the analysis and writing up the report. This was repeatedly scrutinised by the researchers to ensure that individual themes in the data were not under- or over-represented.

\section{Ethical considerations and approval}

Ethical approval was obtained from the University of Lincoln's Ethics Committee and from the Research and Development departments of the two participating NHS trusts. All participants were informed about the voluntary nature of participation and their right to decline and withdraw from the study. Written consent was obtained. Participant identification codes are used

\footnotetext{
1. Full job titles not provided to preserve anonymity.

2. (.) pause

- participant stopped mid-sentence

[ overlapping speech

Italics laughter

Underline emphasis

((brackets)) additional researcher's comments.
} 
Figure 1. Overview of main themes and subthemes relating to professionals' perceptions and experiences of communicating about sexuality after TBI.

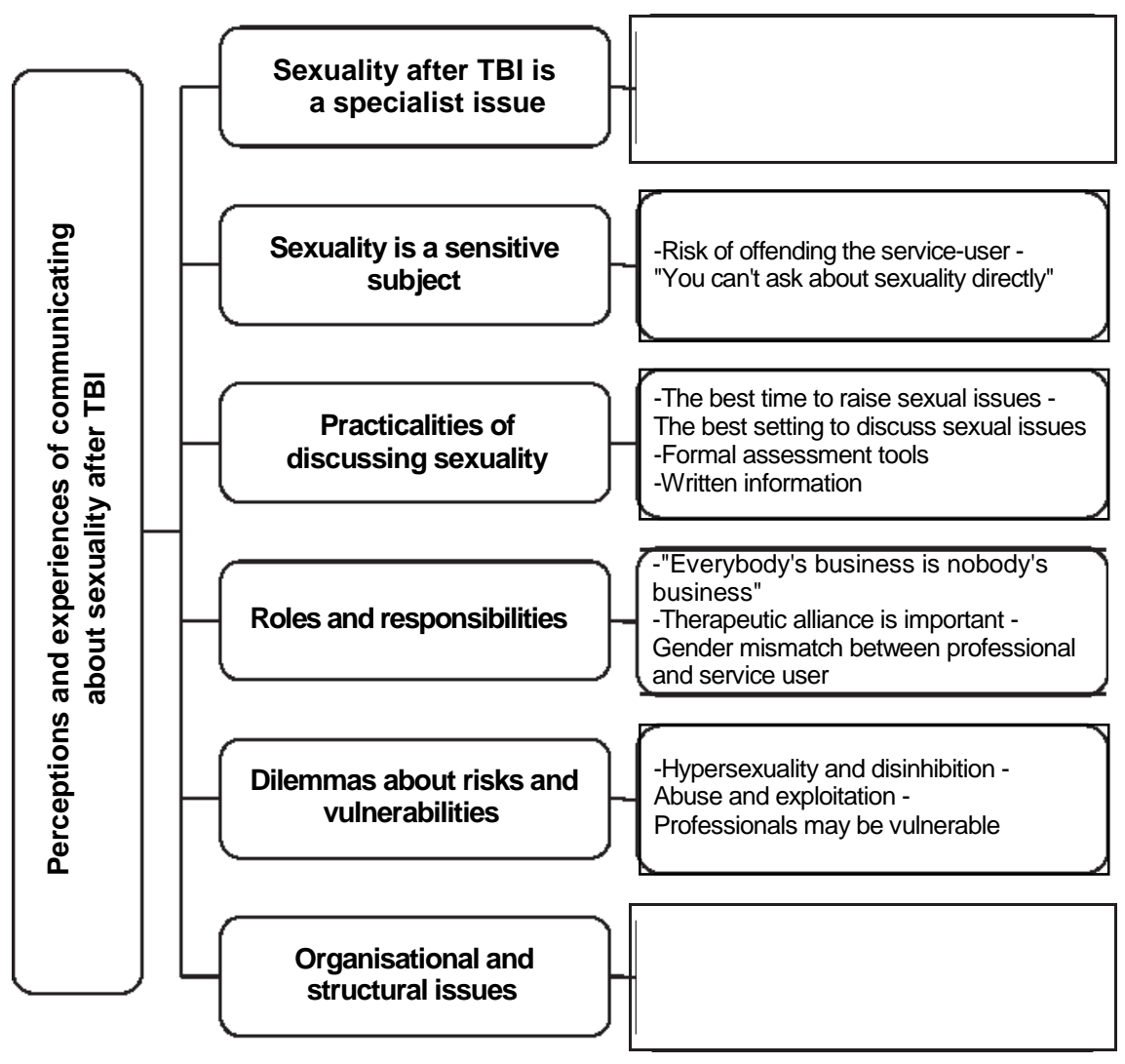

throughout and identifiable details removed to preserve anonymity.

\section{Results}

Altogether, over 1000 initial codes were identified from the focus group data, which were then analysed and grouped into main themes and subthemes, as shown in Figure 1.

It is beyond the scope of this paper to address each of the main themes and subthemes in detail; however, a brief overview of each of the main themes will be provided to highlight the specific issues raised by participants. For ease of reading, themes are displayed as being distinct from each other; however, themes often interlink, and, at times, overlap.

\section{Sexuality after TBI is a specialist issue}

This theme relates to the participants' perception that sexuality is a specialist subject, which requires specialist knowledge, skills and training. At times, a (perceived or actual) lack of knowledge, skills and expertise prevented professionals from opening up discussions about sexuality and also affected how they managed conversations when service-users raised the topic. For example, the participant in the extract below used a deflection technique by changing the subject:

P7:2 ${ }^{3}$ I've had a couple of service users bring the subject up of (.) sex and relationships (.) Erm, it's hard (.) I personally find it hard to talk about because I don't think I have the (.) proper knowledge to be able to explain it to that person. . . so yeah I just sort of skimmed over ((laughter from others)) the subject ((sounds of agreement from others)). Changed the subject

3. This code represents the participant ID. "P7"is the participant number, and " 2 "is the focus group number. "I"represents the interviewer.
Participants highlighted that consultation, supervision and teamwork are all important in overcoming their lack of knowledge, skills and expertise. Several participants reflected on occasions where they had turned to other professionals (either within their team or externally) for advice or support with regards to managing sexual issues. For example, when reflecting on a personal experience of working with a service-user, one participant stated "the psychologist is working with me because it's too much for me to handle"( $\mathrm{P} 1: 3)$.

Participants also highlighted that further education and training would enable them to feel more equipped in dealing with sexual issues, although most made general references to the need for training, and did not specify any areas that training should cover. Some participants who were aware of training available through one particular organisation considered it insufficient:

$\mathrm{P} 7: 2^{4}$ It's not really a proper course though [it's just like a-P1:2

[No. It's like a teaser sort of thing isn't it?

P7:2 One day workshop that gives you very very basic information, and I think that sort of thing needs more formal training

$\mathrm{P} 2: 2$ Yeah

$\mathrm{P} 7: 2$ It's just sort of an awareness raiser

Other participants endorsed the view that "having lectures and having more information wouldn't address that sort of uncomfortableness"(P4:1), instead advocating a more exposure-based approach to building skills in opening up conversations about sexuality; "the more you do it, the easier it is" $(\mathrm{P} 3: 1)$.

4. Where appropriate, we have included the interaction between participants to show agreements, elaborations, endorsements and disagreements. 


\section{Sexuality is a sensitive subject}

This theme relates to the view amongst the participants that sexuality is a sensitive topic that needs to be approached carefully. Some participants wondered whether raising sexuality issues may be perceived as intrusive or inappropriate to service users. The extract below highlights the concern that this may then impact on future rehabilitation and treatment:

$\mathrm{P} 4: 3$. . . particularly in the early days you don't want to upset them or intimidate them or make them feel uncomfortable, "cos we get enough failed to attends

P1:3 Mmm ((indicating agreement with P4:1))

$\mathrm{P} 4: 3$ and people that don't comply to the treatment

This concern about offending the service-user led some participants to wonder how best to raise sexual issues. For instance, one participant reflected on how she "subtly takes opportunities"(P1:3) to discuss sex with one service-user whom she is concerned about with regards to sexual risk-taking, whilst



upsexulisueswihserviceusas(P4:1)

\section{Practicalities of discussing sexuality}

This theme relates to the participants' perceptions of how, when and where to raise sexual issues with service-users. First, participants were concerned about raising sexual issues "too early"in the rehabilitation process for fear of offending the service-user or causing them to become anxious about the potential for sexual difficulties to occur at a later stage. Participants therefore favoured waiting until a later stage before asking about sexual issues. However, one participant highlighted a potential problem with this:

P1:1 Well I guess the problem is that initial assessment becomes the template to carry through for the whole of, the sort of (.) the whole of the rehab intervention (.) and never get round to asking about sex and sexuality (.) or difficulties and changes that might have occurred.

Perhaps as a result of the above concerns, participants tended to favour the reactive approach, waiting until the service-user raises it first. For example, one participant commented,

'I personallywouldn'tbring itupunless the service user ${ }^{\mathrm{d} '}$ '(P62), whilst othess said that they wait for

\section{'hints'ofsexualdifficallies beforeaskingdirectly.}

P1:1 I think we probably work on hints rather than [asking P4:1 [Yeah, I was gonna say, that might come back to the information you gather in the course of speaking to them Whether they hinted that it is an issue

With regards to other practicalities, participants highlighted that opportunities for one-to-one time and privacy would facilitate discussion about sexuality. Others felt that a group setting may be beneficial so that service-users can provide peer-support to each other. Some participants commented that a standardised questionnaire or having written information leaflets available would help them to discuss sexual issues with service-users. For example, one participant felt that providing written information to service-users may create an environment that grants permission and "empowers"them to raise sexual concerns:

P5:4 I don't think they have had this identified. . even on the information leaflet, whether we need to give that information leaflet about the unit, like our unit and say - look, these are the aspects, but if you want to discuss it, feel free to discuss it. So at least they are empowered to say, this is something they can discuss. . . Because actually the patient, they are not aware they are allowed to discuss that with us

\section{Roles and responsibilities}

This theme relates to the dilemmas raised by professionals when considering who should address sexual issues with service-users with TBI. Most participants were against the allocation of a specific professional or discipline to address sexual issues given that it should be the service-users' decision who they decide to raise sexual issues with:

P5:1 I think then maybe it's the client's choice isn't it who's the most appropriate person, because they obviously choose who they want to tell about something so personal

However, one participant (P5:4) used the analogy of "everybody's business is nobody's business"to highlight the negative effects of not allocating a specific professional or discipline to discuss sexuality; i.e. when nobody is responsible for the task, everybody assumes that somebody else will do it, the implication being that nobody does it. The participant in the extract below also reflected on this:

P6:4 You kind of think it's a job for somebody else-like it's not necessary a physio ((physiotherapy)) problem, it's not necessarily an OT ((occupational therapy)) problem, but put us altogether and it is our problem. But I think you sort of expect somebody else to do it rather than (.) you yourself do it

\section{Dilemmas about risk and vulnerabilities}

The perceived risks associated with discussing sexual issues with service-users included the risks associated with sexual exploration, such as service-users accessing the internet, nightclubs, pornography and paid-for-sex. Furthermore, participants reflected on the importance of managing hypersexualised, disinhibited and inappropriate sexual behaviour (particularly in in-patient and day-care centres) as this could potentially place the service-user and/or those around them (including professionals) in vulnerable situations. Some participants reflected on how discussions about sexuality tend only to take place if risks are perceived, the implication being that discussions of sexuality tend to be reactive as opposed to proactive. For example, the extract below follows discussion about one team's involvement in the management of "inappropriate"sexual behaviour:

P1:3 Sometimes we're asked to become involved in all sorts of behavioural issues that we don't particularly (.) class as sexuality. We just- it's just part of what we do

P4:3 I think that's the thing. It seems like it only really comes an issue for us when it's a problem for other people, regardless of whether it becomes a problem for the patient

$\mathrm{P} 1: 3$ Yeah ((indicating agreement with $\mathrm{P} 4: 3)$ )

$\mathrm{P} 4: 3$ If it's a problem with the patient they tend to [keep it to themselves

P1:3 [Yeah, Yeah

P3:3 Yeah ((indicating agreement with P4:3))

$\mathrm{P} 4: 3$ But when it's a problem to other people then everyone shouts about it 


\section{Organisational and structural issues}

This theme encapsulates participants' views about the factors within their organisation and beyond that help or hinder communication with regards to sexuality after TBI. Two participants used the analogy of "opening a can of worms"(P1:1; P5:4) to describe their feelings about opening up issues of sexuality when there is a lack of (or at least a lack of awareness of) available specialist services to refer service-users on to. The extract below illustrates how one participant proposes this theory, an idea which P2:1 had not considered previously:

P1:1 I mean you might be asking a question with this, you know in this area, and erm and then you think what the hell $d o$ I do with it (laughs) ((laughter from others)). . .I mean I'm certainly aware that (.) our model is to deal with it ourselves or to refer on. And where do you refer on to?.. . I don't view it ((sexuality)) as being particularly more difficult to address than any of the others, but it's just that issue about not really being sure about where you take it

P2:1 I'd agree. Yeah, not thought of it like that before

Participants also reflected on how competing pressures of time and recourses mean that sexuality is side-lined in healthcare and rehabilitation settings for other, potentially more important, issues. For example:

P1:3 .. . we're so busy sorting out whether they can walk or talk or-, that we haven't got time a lot of the time. Y'know wewe- And it's almost- almost a luxury isn't it? Cos- ((sighs)) y'know, erm, I mean, does the NHS help you to have sex? (.) I don't know

In the above extract, the participant questioned whether the NHS is the appropriate context to facilitate sex. Participants in another focus group also discussed this subtheme of the sidelining of sexual issues in the context of the wider healthcare system:

P2:1 And the whole wider context, it's just generally not (.) open. Well I think in the NHS it's sort of, do you know what I mean? It's sort of positive about this and positive about that, negative about smoking, positive about-. . . but if you think about it where have you actually seen a poster saying y'know sex is part of your life or whatever. It's just, sort of, not talked about. Eat your five a day and exercise five times a day ${ }^{5}$. Do you know what I'm saying it's not, it's just not-

P5:1 It's just not out there [is it?

$\mathrm{P} 2: 1$ [Yeah it's not out there, that's it $\{\mathrm{P} 5$ name

$\mathrm{P} 1: 1$ It's not viewed as a necessity I guess. In terms of- well I suppose it's never an overall priority for healthcare is it? You don't see the government banging on about (.) targets for sex do you?

Finally, professionals across two focus groups pointed out that unlike other rehabilitation issues, sexuality is not included on formal measures of outcome (P5:4), and this places it as low priority within their organisation.

\section{Discussion}

Studies have shown that the rate of professionals addressing sexual issues after TBI is low [9,21-25]. This study presented a

\section{These refer to specific health campaigns promoted within many} NHS settings. detailed exploration of professionals' experiences and views of discussing sexuality with service-users who have had a TBI. The main themes are discussed below with reference to the existing literature, and recommendations for future research are made.

\section{The complexity of sexuality after TBI and training issues}

Participants conceptualised sexuality after TBI as a complex issue that requires "specialist"skills and expertise. Some professionals felt that training would facilitate communication about sexual issues, which supports findings from the literature [23-25,28]. However, the qualitative methodology of this study enabled further insight into the potential pitfalls of training: First, some participants who were aware of training considered it to be of insufficient level. This is perhaps in line with findings from the literature that noted that only half of professionals who had attended sexuality training found that it had improved their practice, with $20 \%$ stating that it had been of no benefit to them at all [24]. Second, some participants advocated a more exposure-based approach to addressing sexuality. From a behavioural perspective, exposure can be thought of as counteracting avoidance by becoming used to asking about sexuality, until it no longer provokes anxiety. This suggestion has not been highlighted in previous literature and therefore warrants further attention. Finally, participants placed high value on teamwork, supervision and consultation with other professionals in overcoming their lack of knowledge and expertise. Again, this theme warrants further attention.

\section{Perceived topic sensitivity as a hindrance to discussing sexuality}

The perceived sensitive and personal nature of the topic appeared to inhibit open dialogue between professionals and service-users after TBI. In particular, professionals were worried about offending service-users by raising sexual issues "too early"in the rehabilitation process. This theme is consistent with previous research [25,39-42]. However, research indicates that most service-users are not offended by discussion of their sexuality $[43,44]$ and $d o$ expect professionals to make inquiries about sexuality [45], but future research should be conducted specifically with people who have experienced a TBI.

\section{Reactive versus proactive ways of discussing sexuality}

The findings indicated that professionals tended to wait until the service-user raised sexual issues first, a finding consistent with previous research [22,23]. However, this reactive approach is considered problematic given the finding that service-users believe it to be the professionals' role to start the conversation [46], alongside evidence that service-users are concerned about raising the topic for fear of embarrassing the professional or being told that concerns are "just in your head"[47]. Furthermore, service-users may be unaware of the link between TBI and sexual difficulties, thus deeming it to be irrelevant to the rehabilitation professional [7]. As a result, many sexual concerns could be going undetected.

Professionals highlighted that formal assessment tools and the provision of written information would enable them to address sexual issues more proactively, suggestions which have been made previously [7]. Professionals also highlighted the possibility of service-user groups/peer support to facilitate discussion about sexuality. Similarly, two-thirds of the professionals in Katz \& Aloni's study [25] recommended group therapy as a preferred method for sexual rehabilitation post-TBI. 


\section{Roles and responsibilities}

Participants were reluctant to nominate specific professionals to discuss sexual issues with service-users, arguing that under ideal circumstances, the service-user should be able to choose whom he or she feels comfortable with for such discussions. This supports findings from the literature [24]. Davis \& Taylor [48] have also indicated that addressing sexuality requires a multidisciplinary approach and therefore should not be the responsibility of a single professional. However, there are two main limitations of this approach: First, placing the onus on the service-user to raise sexual issues first is potentially problematic for the reasons highlighted earlier and second, and as highlighted by the participants in one focus group, there is potential for members of the team to assume that professionals from other disciplines have addressed, or will address, sexual concerns. Indeed, Ducharme [49] found that service-users with spinal cord injury often left rehabilitation with no information about sexuality for this very reason.

\section{Balancing risks and vulnerabilities with information- giving and support}

Professionals highlighted concerns about service-users with TBI being sexually disinhibited, a link backed up by research [50-52]. Furthermore, professionals felt that service-users may be more vulnerable to abuse and exploitation as a result of their TBI. Although no studies have investigated the vulnerability of people with TBI specifically, evidence does suggest that people with disabilities more generally are more likely to experience physical, sexual and emotional abuse than any other group [5355].

These issues should of course be given serious attention; however, it could be argued that this risk should not be used as a "smokescreen"to deny service-users the opportunity to find a sexual identity and expression: "just as the labelling of disabled people as asexual is inappropriate, so too is an 'overprotective'

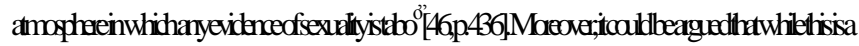

risk, it is an inherent risk; i.e. there is no evidence that it emerges as the result of discussing sexuality in clinical or therapeutic encounters. In fact, blockage of age-appropriate and socially appropriate sexual information or experiences may actually serve to increase inappropriate sexual behaviour [56], as well as the incidence of sexual abuse [55].

Some professionals reflected on how sexual issues tend to only be addressed when they become a "problem for other people", presumably in an attempt to reduce the future possibility of risky or inappropriate behaviour occurring. Indeed, Miller has stated that "professionals frequently ignore, avoid, or quite innocently overlook the sexual needs of their patients until they begin to exhibit sexually inappropriate behaviour" $[48$, p. 19].

\section{Systemic and organisational hurdles to discussing sexuality}

Dyer \& das Nair's [29] review of qualitative studies found that wider systemic factors such as limited time, resources and privacy can prevent discussions about sexuality from taking place, and indeed, professionals in this study raised the importance of these issues. Professionals also highlighted that sexuality is side-lined within organisations, which supports findings from the literature [57-59]. Professionals' perceptions that service-users share their focus on "walking and talking"may well be congruent with service-users' expectations, but further research is required to investigate this. However, research from other healthcare settings has shown that service-users do want and expect professionals to discuss sexual issues [60,61].
Related to this, professionals highlighted that low priority is attributed to sexuality given that it is not included on formal measures of outcome. Indeed, sexuality is not included on the "UK Functional Independence Measure plus Functional Assessment Measure"(UK FIM PFAM) [62], which was specifically designed for use in brain injury [63] and has recently been widely introduced across rehabilitation settings. Furthermore, one professional highlighted that, and as a result of this, there are no measurable consequences for not addressing sexual issues. This subtheme is significant as it has not been previously highlighted in the literature, warranting further attention in future research.

\section{Implications for practice, policy and training}

Through their contact with service-users with a TBI, professionals have an important role in encouraging discussions about sexual concerns. Sexuality is a particularly important area to address given the high incidence of sexuality difficulties post-TBI, combined with the known importance of sexuality for overall wellbeing and quality of life. Furthermore, research has indicated that service-users do not generally discuss sexuality with family and friends [64].

We believe that the reactive approach taken by the majority of professionals is unsatisfactory, and a more proactive approach is recommended. This is also important in light of the Department of Health's ambition to strengthen the role of healthcare in the management of sexual health and wellbeing [65]. According to Herson et al. [66] "anyone in the helping professions, regardless of job title, can provide some level of sexuality information”(p. 149).

The PLISSIT model [67] has been used over the past 30 years by professionals working to address the sexual wellbeing of individuals with acquired disability and chronic illness [68]. The acronym PLISSIT signifies the four levels of intervention: Permission to discuss sexuality, provision of limited information regarding sexuality, specific suggestions regarding the person's sexual issues and intensive therapy with an expert when needed.

Professionals are not expected to offer interventions at all levels and are therefore not required to have "specialist"skills. In some cases, it may be most appropriate for rehabilitation services to only screen for and identify concerns, before referring serviceusers on for more specialist assessment and/or treatment [67]. However, ensuring these individuals are identified and referred is an important first step in service provision. Indeed, Taylor \& Davis [48,68] later extended the model (the Ex-PLISSIT model), arguing that all levels should begin with explicit permission. At a minimum, this may involve letting service-users know that sexuality is a legitimate area for discussion in the rehabilitation setting.

As suggested by some participants, it would be beneficial for sexuality to be incorporated into routine assessments. This may involve asking service-users how their TBI has affected the way they see themselves as a male or female [61]. The question could then be followed by asking if they have any concerns about how their TBI has influenced their sexuality [69]. Having information resources readily available also contributes to an environment that grants service-users permission to think and talk about sexuality in relation to their TBI.

Getting sexuality issues into TBI rehabilitation is dependent upon much more than professionals' motivation: As highlighted by the participants, organisation and structural factors play an important role. Services need to be adequately staffed and resourced, and professionals need to receive adequate supervision. In services where this is not attainable, or where areas are outside of the scope of practice or expertise, it is important for agencies 
to develop links with specialist sexual health or therapy services to address these needs. Furthermore, explicit policies and procedures are required to solidify a team approach on addressing and managing sexuality issues and to provide consistency in the delivery of care. Policies should find an appropriate balance between enabling people with TBI to have their sexual rights and needs met, whilst reducing the risks of abuse and exploitation.

Finally, taboos continue to represent an important challenge; and one which Cellek \& Giraldi [46] believe can only be resolved through improved education at both undergraduate and postgraduate levels. This would help to raise awareness of the importance of sexuality for service-users in terms of general wellbeing and quality of life. Training should be available to all staff and should include: Information on how biological, psychological and social changes after TBI can impact on sexuality, the impact of medication, sexuality throughout the life-cycle, cultural differences, socially acceptable sexual expression, contraception, issues for lesbian, gay, bisexual and transgender TBI serviceusers, appropriate resources for sexual exploration (such as dating), identification and management of risk as well as the law and policies that are in place within the specific organisation. Professionals are also likely to benefit from ongoing in-service opportunities for open discussion, exploration and clarification of their values, attitudes, biases and comfort levels in relation to sexuality $[13,22,70,71]$. It would also be important for training programs to be evaluated in the future.

\section{Limitations of this study}

The generalisability of the findings is potentially limited by the small homogenous sample and the researchers' subjective interpretation of the data. Whilst a number of quality assurance measures were put in place, rigour could have potentially been enhanced by sending transcripts or quotations to participants to check for accuracy and to comment on the researcher's interpretations. It is also important to consider how the focus group context may have impacted on the findings. For example, Sim [35] has suggested that focus groups may lead to the 'censoring' of opinions or experiences that differ from the majority view of the group, leading to a false impression of conformity amongst participants. However, a number of authors have suggested that focus groups can enhance openness and disclosure [30,31].

\section{Conclusions}

Service-users who have had a TBI and their families are dependent upon professionals for assessment, guidance, education and support in dealing with sexual problems, yet sexuality has been a neglected area in TBI rehabilitation. This study explored the perceptions and experiences of rehabilitation professionals in discussing sexuality with service-users who have had a TBI, with similar barriers and facilitating factors being identified to those in previous literature.

This paper outlines a number of implications for clinical practice, training and the development of policy, in order that sexuality becomes accepted as an integral component of holistic rehabilitation. It is recommended that a more proactive approach to managing sexual issues is taken in clinical practice. However, without support for professionals in the form of the development of policy, on-going training, supervision and adequate staffing, sexuality issues are in danger of being neglected.

\section{Acknowledgements}

We would like to thank all the professionals who were involved in organising and participating in the focus groups and Dr Nigel
Schofield for his professional help and advice in conducting this study.

\section{Declarations of interest}

The authors report no declarations of interest.

\section{References}

1. Rathus SA, Nevid JS, Fichner-Rathus L, et al. Human sexuality in a world of diversity. 2nd ed. New Jersey: Pearson Education; 2005.

2. World Health Organization [internet]. Sexuality: draft working definition. 2012. Available from: http://www.who.int/reproductivehealth/topics/gender_rights/sexual_health/en/ [last accessed 7 Nov 2012].

3. World Health Organization. International Classification of Functioning, Disability and Health (ICF). Geneva: World Health Organisation; 2001.

4. Department of Health. Healthy lives, health people: our strategy for public health in England. 2010. Available from: http://www.dh.go$\mathrm{v}$.uk/prod consum dh/groups/dh digitalassets/documents/digitalasset/dh 127424.pdf [last accessed 7 Nov 2012].

5. Dolin'ska-zygmunt G, Nomejko G. Sexual satisfaction's contribution to a sense of quality of life in early adulthood. Pol $\mathbf{J}$ App Psychol 2011;9:65-73.

6. Blackerby W. Disruption of sexuality following a head injury. National Head Injury Foundation News 1987;7:8.

7. Simpson G. Addressing the sexual concerns of persons with traumatic brain injury in rehabilitation settings: a framework for action. Brain Impair 2001;2:97-108.

8. O'Carroll RE, Woodrow J, Maroun F. Psychosexual and psychosocial sequelae of closed head injury. Brain Inj 1991;5:303-13.

9. Kreuter M, Dahllöf AG, Gudjonsson G, Sullivan M, Siösteen A. Sexual adjustment and its predictors after traumatic brain injury. Brain Inj 1998;12:349-68.

10. Kreutzer JS, Zasler ND. Psychosexual consequences of traumatic brain injury: methodology and preliminary findings. Brain Inj 1989; 3:177-86.

11. Ponsford J. Sexual changes associated with traumatic brain injury. Neuropsychol Rehabil 2003;13:275-89.

12. Kosteljanetz M, Jensen TS, Norgard B, et al. Sexual and hypothalamic dysfunction in the postconcussional syndrome. Acta Neurol Scand 1981;63:169-80.

13. Blackerby W. A treatment model for sexuality disturbance following brain injury. J Head Trauma Rehabil 1990;5:73-82.

14. Arango-Lasprilla JC, Ketchum JM, Dezfulian T, et al. Predictors of marital stability 2 years following traumatic brain injury. Brain Inj 2008;22:565-74.

15. Godwin EE, Kreutzer JS, Arango-lasprilla JC, Lehan TJ. Marriage after brain injury: review, analysis, and research recommendations. Health 2011;26:43-55.

16. Wedcliffe T, Ross E. The psychological effects of traumatic brain injury: neurobehavioural and personality changes. S Afr J Commun Disord 2001;48:77-99.

17. Johnson CL, Resch JA, Elliot TR, et al. Family satisfaction predicts life satisfaction trajectories over the first 5 years after traumatic brain injury. Rehabil Psychol 2010;55:180-7.

18. Wood RL, Yurdakul LK. Change in relationship status following traumatic brain injury. Brain inj 1997;11:491-501.

19. Oddy M, Coughlan T, Tyerman A, Jenkins D. Sexual adjustment after closed head injury: a further follow-up seven years after injury. J Neurol Neurosurg Psychiatry 1985;48:564-8.

20. Tate RL, Lulham JM, Broe GA, et al. Psychosocial outcome for the survivors of severe blunt injury: the results from a consecutive series of 100 patients. J Neurol Neurosurg Psychiatry 1989;52:1128-34.

21. Zinn W. Sexual problems in rehabilitation: analysis and solutions. Int Rehabil Med 1981;3:18-25.

22. Ducharme S, Gill KM. Sexual values, training and professional roles. J Head Trauma Rehabil 1990;5:38-45.

23. Hough S. Sexuality within the head-injury rehabilitation setting: a staff's perspective. Psychol Rep 1989;65:745-6.

24. Haboubi NH, Lincoln N. Views of health professionals on discussing sexual issues with patients. Disabil Rehabil 2003;25:291-6.

25. Katz S, Aloni R. Sexual dysfunction of persons after traumatic brain injury: perceptions of professionals. IJRR 1999;22:45-53. 
26. Taleporos G, McCabe MP. The impact of sexual esteem, body image, and sexual satisfaction on psychological well-being in people with physical disability. Sex Disabil 2002;20:177-83.

27. Baker M, Shears S. Sexuality training for health and social care professionals working with people with an acquired brain injury. Soc Care Neurodisabil 2010;1:4-12.

28. Davis D, Schneider L. Ramifications of traumatic brain injury for sexuality. J Head Trauma Rehabil 1990;5:31-7.

29. Dyer K, das Nair R. Why don't healthcare professionals talk about sex? A systematic review of recent qualitative Studies conducted in the United Kingdom. J Sex Med 2013;10:2658-70.

30. Kitzinger J. Qualitative research: introducing focus groups. BMJ 1995;311:299-302.

31. Wilkinson S. Focus groups in health research. Health Psychol 1998; 3:329-48.

32. Madriz E. Focus groups in feminist research. In: Denzin N, Lincoln Y, eds. Handbook of qualitative research. 2nd ed. Thousand Oaks, (CA): Sage; 2000:835-50.

33. Jefferson G. Transcription notation. In: Atkinson JM, Heritage J, eds. Structures of social interaction. New York: Cambridge University Press; 1984:ix-xvi.

34. Cote-Arsenault D, Morrison-Beedy D. Practical advice for planning and conducting focus groups. Nurs Res 1999;48:280-3.

35. Sim J. Collecting and analysing qualitative data: issues raised by the focus group. J Adv Nurs 1998;28:345-52.

36. Braun V, Clarke V. Using thematic analysis in psychology. Qual Res Psychol 2006;3:77-101.

37. Lincoln YS, Guba E. Naturalistic inquiry. Beverley Hills (CA): Sage Publications; 1985.

38. Creswell JW, Miller DL. Determining validity in qualitative inquiry. Theory Into Pract 2000;39:124-30.

39. Gott M, Hinchliff S, Galena E. General practitioner attitudes to discussing sexual health issues with older people. Soc Sci Med 2004;58:2093-103.

40. Dattilo J, Brewer MK. Assessing clients' sexual health as a component of holistic nursing practice: senior nursing students share their experiences. J Holist Nurs 2005;23:208-19.

41. McLaughlin J, Cregan A. Sexuality in stroke care: a neglected quality of life issue in stroke rehabilitation? A pilot study. Sex Disabil 2005;23:213-26.

42. Gott M, Galena E, Hinchliff S, Elford H. "Opening a can of worms": GP and practice nurse barriers to talking about sexual health in primary care. Fam Pract 2004;21:528-36.

43. Rubin R. Communication about sexual problems in male patients with multiple sclerosis. Nurs Stand 2005;19:33-7.

44. Matocha LK, Waterhouse JK. Current nursing practice related to sexuality. Res Nurs Health 1993;16:371-8.

45. Gianotten W, Bender J, Post M, Hoing M. Training in sexology for medical and paramedical professionals: a model for the rehabilitation setting. Sex Relation Ther 2006;21:303-17.

46. Cellek S, Giraldi A. Challenges in sexual medicine. Nature reviews Urology 2012;9:537-42.

47. Marwick C. Survey says patients expect little physician help on sex JAMA 1999;281:2132-74.

48. Davis S, Taylor B. From PLISSIT to ExPLISSIT. In: Davis S, ed. Rehabilitation: the use of theories and models in practice. Edinburgh, UK: Churchill Livingstone; 2006:101-30.
49. Ducharme $\mathrm{S}$. Innovations in sexual health for men with spinal cord injury. Sex Update 1991;4:8-12.

50. Miller BL, Cummings JL, Mcintyre H, et al. Hypersexuality or altered sexual preference following brain injury. J Neurol Neurosurg Psychiatry 1986;49:867-73.

51. Miller L. Sex and the brain-injured patient: regaining love, pleasure and intimacy. J Cog Rehabil 1994;12:12-20.

52. Sabhesan S, Natarajan M. Sexual behavior after head injury in Indian men and women. Arch Sex Behav 1989;18:349-56.

53. Ducharme S, Gill KM. Sexuality after spinal cord injury: answers to your questions. Baltimore: Paul H Brookes; 1997.

54. Westcott H. Abuse of children and adults who are disabled. In: French S, ed. On equal terms: working with disabled people. London, UK: Butterworth Heinemann; 1994:190-206.

55. Earle S. Disability, facilitated sex and the role of the nurse. J Adv Nurs 2001;36:433-40.

56. Harris AJR, Tough S. Should actuarial risk assessments be used with sex offenders who are intellectually disabled. J Appl Res Intellect Disabil 2004; 17:254-41.

57. Hordern AJ, Street AF. Communicating about patient sexuality and intimacy after cancer: mismatched expectations and unmet needs. Med J Aust 2007;186:224-7.

58. Guthrie C. Nurses' perceptions of sexuality relating to patient care. J Clin Nurs 1999;8:313-21.

59. Price B. Sexuality: raising the issue with patients. Canc Nurs Pract 2010;9:29-35.

60. Northcott R, Chard G. Sexual aspects of rehabilitation: the client's perspective. Br J Occup Ther 2000;63:412-18.

61. Waterhouse J, Metcalfe M. Attitudes towards nurses discussing sexual concerns with patients. J Adv Nurs 1991;16:1048-54.

62. Turner-Stokes L, Nyein K, Turner-Stokes T, Gatehouse C. The UK FIMpFAM: development and evaluation. Clinl Rehabil 1999;13: 277-87.

63. Hall KM, Hamilton BB, Gordon WA, Zasler ND. Characteristics and comparisons of functional assessment indices: disability rating scale, functional independence measure, and functional assessment measure. J Head Trauma Rehabil 1993;8:60-74.

64. Mccabe MP, Cummins RA, Deeks AA. Sexuality and quality of life among people with physical disability. Sex Disabil 2000;18: 11523.

65. Department of Health. The national strategy for sexual health and HIV. London, UK: Department of Health; 2001

66. Herson L, Hart KA, Gordon MJ, Rintala DH. Identifying and overcoming barriers to providing sexuality information in the clinical setting. Rehabil Nurs 1999;24:148-51.

67. Annon J. The PLISSIT model: a proposed conceptual scheme of the behavioural treatment of sexual problems. J Sex Educ Ther 1976;2: $1-15$.

68. Taylor B, Davis S. The Extended PLISSIT model for addressing the sexual wellbeing of individuals with an acquired disability or chronic illness. Sex Disabil 2007;25:135-9.

69. Magnan MA, Reynolds KE, Galvin EA. Barriers to addressing patient sexuality in nursing practice. Medsurg Nurs 2005;14: 2829.

70. Medlar T, Medlar J. Nursing management of sexual issues. J Head Trauma Rehabil 1990;5:46-51.

71. Glass CA. Addressing psychosexual dysfunction in neurological rehabilitation settings. Sex Disabil 1995:251-60. 